\title{
The mouse bone metabolome is sexually dimorphic and is associated with whole bone strength
}

Authors: Hope D. Welhaven ${ }^{1}$, Ghazal Vahidi², Seth T. Walk ${ }^{3}$, Brian Bothner ${ }^{1},{ }^{*}$ Chelsea M. Heveran ${ }^{2}$, Ronald K. June ${ }^{2,3}$

${ }^{1}$ Department of Chemistry \& Biochemistry, Montana State University, Bozeman, MT 59717

15 Department of Mechanical \& Industrial Engineering, Montana State University, Bozeman, MT, 59717

${ }^{3}$ Department of Microbiology \& Immunology, Montana State University, Bozeman, MT, 59717

Co-Corresponding Authors

${ }^{*}$ Chelsea M. Heveran, Ph.D.

Dept. of Mechanical \& Industrial Engineering

35 Montana State University

PO Box 173800, Bozeman, MT 59717-3800

Phone: (406) 994-5941; Fax: (406) 994-6292; E-mail: chelsea.heveran@montana.edu

${ }^{*}$ Ronald K. June, Ph.D.

40 Dept. of Mechanical \& Industrial Engineering

Montana State University

PO Box 173800, Bozeman, MT 59717-3800

Phone: (406) 994-5941; Fax: (406) 994-6292; E-mail: rjune@montana.edu 


\section{Abstract}

The material properties of bone tissue depend on the activity of remodeling bone cells, but the impact of bone cell metabolism on bone tissue is uncertain. To date, the metabolome of bone has not been evaluated for cortical bone, bone marrow, or whole bone including both tissue types. Furthermore, it is of particular interest whether the cortical bone metabolome reflects the sexual dimorphism observed in cortical bone material properties. We hypothesized that the metabolome of cortical bone differs from that of bone marrow, and that the cortical bone metabolome is sexually dimorphic. We first evaluated the metabolic profiles of isolated cortical bone, bone marrow, and whole

55 bone for 20 -week female C57BI/6 mice $(n=10)$. We then compared metabolic profiles for isolated cortical bone from a separate group of 20 -week female and male C57BI6/mice ( $n=10 /$ sex). Femurs from the same mice were evaluated for flexural material properties. Strength groupings (high strength males, high strength females, low strength males) were utilized to inform comparisons in the isolated humerus cortical

60 bone metabolome. The metabolome of isolated cortical bone, bone marrow, and whole bone are distinct. The isolated cortical bone metabolome is also distinct between males and females. The female mice show evidence of lipid metabolism, whereas male mice show evidence of amino acid metabolism. Finally, 12 metabolic pathways were differentially regulated between bones that differed in strength. High-strength bones

65 from both male and female mice included metabolites associated with tryptophan and purine metabolism. Taken together, these data demonstrate the power of metabolomics to provide insight into the effects of metabolism on bone physiology. These data add to an intricate picture of bone as an organ that is sexually dimorphic both in material and metabolomic profiles.

Keywords: bone quality, bone strength, metabolomics, sex differences 


\section{Introduction}

In many cases, bone material properties are sexually dimorphic but the dependence of these properties on bone cell metabolism is uncertain. While more studies investigating sex differences in bone quality are needed, female rodent femurs are reported as having higher mineral:matrix ratio ${ }^{(1)}$, and are, in some studies, stronger or stiffer than males ${ }^{(2-4)}$. Bone quality depends on bone tissue maturity and therefore on the activities on remodeling bone cells such as osteoblasts, osteoclasts, and osteocytes ${ }^{(5-8)}$. Both synthesizing and removing bone requires ATP. Therefore, both the health and activity of bone remodeling greatly rely on central energy metabolism and may be fundamental to the development of high-quality bone ${ }^{(9-11)}$. Further, it is possible that differences in central energy metabolism regulation may be influenced by sex.

Bone cells use a range of metabolic pathways to maintain energy balance, which may depend on sex ${ }^{(12)}$, aging ${ }^{(13,14)}$, and disease ${ }^{(1,15-17)}$. For example, in aging mouse bone, oxidative phosphorylation is impaired and mitochondria function is compromised ${ }^{(13,18)}$.

90 Further, Kim et al., investigated the effects of diet, sex, and enzyme expression in transgenic osteoblasts in vitro. Osteoblasts from transgenic mice with targeted disruption of carnitine palmitoyltransferase 2 (Cpt2) showed impaired fatty acid metabolism, decreased mobilization of glucose, and had downstream effects on lipid homeostasis leading to accumulation of lipids ${ }^{(12)}$. These Cpt2-dependent changes in energy metabolism were greater in females demonstrating the importance of sexual dimorphism in metabolic processes.

Sex differences in the metabolome are not understood in part because the metabolome of cortical bone is not well defined. Metabolomics is a powerful tool that has the

100 potential to provide novel insight into the physiology of bone cells and of bone as an organ. Metabolomics is the study of large numbers of small molecules called metabolites. The generated metabolomic profiles contain data on thousands of metabolites that represent cellular physiology. Metabolomics has the ability to identify and quantify metabolites, as well as study the influence of various metabolic pathways 105 on the phenotype, organism, or sample of interest ${ }^{(19)}$. Metabolomic profiling has been used for orthopedic tissues including synovial fluid ${ }^{(20-25)}$ and serum ${ }^{(26-28)}$ to understand disease progression (e.g., osteoarthritis) ${ }^{(27,29-34)}$, the effects of injury ${ }^{(22)}$ and mechanical loading ${ }^{(35,36)}$.

110 Only a single study to date has performed metabolomic profiling on bone itself(29). Zhao et al applied metabolomics and lipidomics to investigate metabolic dysregulation and mechanisms of bone in a mouse model of postmenopausal osteoporosis ${ }^{(29)}$. Using metabolomic analysis of flushed femurs, they detected amino acid and lipid related metabolic pathways and identified potential biomarkers influenced by ovariectomy ${ }^{(29)}$.

115 While this study provided insights into the metabolome of bone, it is still unknown how the metabolomes of isolated bone (i.e., flushed of marrow), whole bone, and marrow differ. Further, sex differences in bone metabolism are still unknown. 
120 isolated cortical bone, bone marrow, and whole bone (i.e., cortical bone and marrow), (2) assess if the cortical bone metabolome is sexually dimorphic, and (3) determine if metabolomic differences correspond with whole bone strength, a sexually dimorphic material property.

\section{Methods}

\subsection{Animals}

Two sets of mice were utilized for this study (total $n=30$ ). First, ten C57BI/6J female 130 mice were utilized to compare the metabolomes of whole bone, isolated cortical bone, and bone marrow. These mice were purchased from Jackson Labs and equilibrated to the Montana State University animal facility for a minimum of 3 weeks. Second, twenty C57BI/6J mice (female, $n=10$; male, $n=10$ ) were utilized to evaluate sex differences in the cortical bone metabolome. These mice were born and raised at Montana State 135 University.

All mice were housed in cages of 3-5 mice and fed a standard chow fed diet ad libitum (PicoLab Rodent Diet 20, 20\% protein). All 30 mice were euthanized via cervical dislocation at age 20-21 weeks. All animal procedures were approved by the

140 Institutional Animal Care and Use Committee at Montana State University. Investigators remained blinded to mouse sex during data collection and analyses.

\subsection{Metabolomics}

\section{$145 \quad$ 2.2.1 Experimental design to assess metabolic differences in various tissues}

We first evaluated differences in metabolomic profiles of isolated cortical bone, bone marrow, and whole bone for humeri from female mice $(n=10)$. To isolate bone marrow from cortical bone, the distal and proximal ends of right humeri were removed and the

150 cortical shaft flushed with phosphate-buffered saline (PBS). Both cortical bone and marrow were preserved for analyses. The left humerus remained whole.

To extract bone metabolites, whole humeri and isolated cortical bone were placed in liquid nitrogen for 2 hours and pulverized to a powder using an autoclaved aluminum 155 cold sink, rods, and a hammer to optimize extraction. Bone powder was extracted with 3:1 methanol:acetone. Samples were subjected to 5 cycles, each consisting of 1 minute of vortexing followed by macromolecule precipitation at $-20^{\circ} \mathrm{C}$ for 4 minutes. Samples were stored overnight at $-20^{\circ} \mathrm{C}$ to allow for precipitation of remaining macromolecules. The next day, samples were centrifuged to remove cells and debris, supernatant 160 containing metabolites was collected, and dried down via vacuum concentration. Once the supernatant was isolated and dried, metabolites were resuspended with 1:1 acetonitrile:water (Figure 1). 
Flushed bone marrow underwent a similar extraction protocol. To extract bone marrow metabolites, $1 \mathrm{~mL}$ of 70:30 methanol:acetone was added and the mixture was subjected to 5 cycles of vortexing and $-20^{\circ} \mathrm{C}$ precipitation. Samples were then stored overnight at $-20^{\circ} \mathrm{C}$ to precipitate any remaining macromolecules. The next day, samples were centrifuged and supernatant containing metabolites was dried down via vacuum concentration. Dried metabolites were resuspended with 1:1 acetonitrile:water (Figure

170 1). All solvents used were HPLC-grade or higher.

\subsubsection{Evaluation of sex differences in isolated cortical humerus metabolomic profiles}

175 We investigated sex differences in metabolomic profiles of cortical humeri for C57BI/6 mice (females, $n=10$; males, $n=10$ ). Left humeri were dissected, cleaned, and bone marrow flushed to isolate cortical bone tissue. Bones were stored in PBS-dampened gauze at $-20^{\circ} \mathrm{C}$ after dissection until the metabolite extraction. For isolated bone metabolite extraction used the protocol described in 2.2.1.

Following metabolite extraction of whole bone, bone marrow, or isolated bone, all samples $(n=30)$ were analyzed by Liquid Chromatography Mass Spectrometry (LCMS) using an Agilent 1290 LC coupled to an Agilent 6538 Q-TOF mass spectrometer in positive mode (resolution: 25,000 FWHM, accuracy: +/- 5 ppm). A Cogent Diamond

185 Hydride HIILIC chromatography column was utilized $(2.2 \mu \mathrm{M}, 120 \AA$, $150 \mathrm{~mm} \times 2.1 \mathrm{~mm}$, MicroSolv Leland, NC, United States). 2-5 $\mu \mathrm{L}$ of sample was injected and blank samples were analyzed every 7-10 samples for quality control to prevent spectral drift and contamination. Agilent Masshunter Qualitative Analysis software was used to identify and export peak intensity values for $\mathrm{m} / \mathrm{z}$ values in the experimental sample set. LCMS

190 data was then exported and converted for analysis using XCMS. Differential analysis of mass features was completed using Metaboanalyst. KEGG was utilized for feature identification.

\subsection{Bone marrow adiposity}

Proximal tibiae were dissected and fixed for 18 hours in $10 \%$ neutral buffered formalin. Tibiae were then decalcified with EDTA, dehydrated in a graded ethanol series and embedded in paraffin. $5 \mu \mathrm{m}$ sections were cut longitudinally onto glass slides and stained with hematoxylin and eosin (H\&E) per standard protocols.

Sections were imaged using a Nikon Eclipse E-800 and Universal Imaging Corporation's MetaVue software (version 7.4.6). Images were taken with a 4x objective (909 pixels / $1 \mathrm{~mm}$ ). A central section proximal tibia was selected for analyses. Adipocytes were manually segmented, counted, and measured using the iPad app 205 YouDoodle and custom MATLAB code. Measurements included mean adipocyte area $\left(\mathrm{mm}^{2}\right)$, marrow cavity area $\left(\mathrm{mm}^{2}\right)$, and adipocyte number density (number of adipocytes per marrow cavity area). 
210 confirm effectiveness of the marrow flushing process. These sections were prepared, imaged, and analyzed consistent with the description for tibiae.

\subsection{Whole-bone mechanical and material properties}

215 Bones were thawed for MicroCT (Scanco uCT40) analysis and afterwards refrozen. Scans were acquired using a $10 \mu \mathrm{m}^{3}$ isotropic voxel size, $70 \mathrm{kVP}, 114 \mu \mathrm{A}, 200 \mathrm{~ms}$ integration time, and were subjected to Gaussian filtration and segmentation. Image acquisition and analysis adhered to the JBMR guidelines ${ }^{(37)}$.

220 Femurs were harvested and stored at $-20^{\circ} \mathrm{C}$ in PBS-dampened gauze. Thawed left femurs were assessed in 50 transverse microCT slices over a length of $500 \mu \mathrm{m}$ at the mid-diaphysis including the outermost edge of the cortex. Left femurs were frozen and thawed once before three-point bending ( $1 \mathrm{kN}$ load cell, Instron 5543). The test was performed to failure at a rate of $5 \mathrm{~mm} / \mathrm{min}$ on a custom fixture with an $8 \mathrm{~mm}$ span.

225 Femur hydration was maintained before testing using PBS. Using load-displacement data and the $I_{\min }$ and $\mathrm{C}_{\min }$ values from microCT, modulus, yield strength, maximum strength, and toughness were calculated using standard equations for the mouse femur ${ }^{(38)}$.

230 Right femurs were assessed for notched fracture toughness ${ }^{(39)}$. Thawed femurs were hydrated with PBS and notched on the posterior side to a target of $1 / 3^{\text {rd }}$ of the anteriorposterior width on the posterior surface using a custom precision saw. Notched femurs were then tested in three-point bending ( $1 \mathrm{kN}$ load cell, Instron 5543, Norwood, MA) at a rate of $0.001 \mathrm{~mm} / \mathrm{sec}$ using an $8 \mathrm{~mm}$ span until failure. Femurs were hydrated with PBS

235 between notching and testing. Femurs were tested with the notch face down. Fractured femurs were cleaned of marrow and dried overnight. Fracture surfaces were then imaged using field emission scanning electron microscopy (FESEM, Zeiss SUPRA 55VP) in variable pressure mode (VPSE, $20 \mathrm{~Pa}, 15 \mathrm{kV}$ ) and analyzed using a custom MATLAB code to quantify cortical geometry and initial notch half angle. Fracture

240 toughness $\left(\mathrm{K}_{\mathrm{c}}\right)$ was calculated from the initial notch angle and the maximum load. Notch geometry met the thick-walled cylinder crack propagation model criteria, with half-notch angles less than $110^{\circ}$.

To assess how differences in bone strength associate with metabolic profiles, we

245 defined high- and low- strength groups for additional comparisons. Males demonstrated higher variability of strength than females. 'High strength' and 'low strength' groups were defined on a threshold of $+/-7 \%$ away from the mean strength for males. For females, high strength bones were those $>5 \%$ greater than the female group mean.

\section{$250 \quad 2.5$ Statistical analysis}

The effect of sex on all bone outcomes except metabolomic measures was tested using two-sample t tests (Minitab, v.19). Data were checked for normality. Non-normal data 
255 priori to $<0.05$.

MetaboAnalyst was utilized to assess metabolomic data. Using standard procedures $^{(22,24)}$, raw data were log transformed, standardized, and auto-scaled (mean centered divided by standard deviation per variable) prior to analysis. Analyses included

260 hierarchical cluster analysis (HCA), principal component analysis (PCA), partial least squares-discriminant analysis (PLS-DA), volcano plot analysis, t-test, and fold change.

In brief, HCA and PCA are unsupervised multivariate statistical analyses that assess differences in metabolomic profiles between experimental groups. HCA identifies sub-

265 groups of samples and determines differences between groups. PCA is an unsupervised technique that finds components (PCs) of the dataset that align with the overall variation to examine the underlying structure of the data. PLS-DA is a supervised analysis that partitions variation within the data base on a priori knowledge of experimental groups. PLS-DA further calculates a variable importance in projection

270 (VIP) score to quantify how much each metabolite feature contributes to discriminating between cohorts. Taken together, these three approaches, HCA, PCA, and PLS-DA, provide a global view of the thousands of metabolites comprising the metabolome. This view describes how experimental groups are both similar and different. These complementary analyses provide insight into interactions occurring at the metabolic

275 level.

Finally, volcano plot and fold change analyses are utilized to identify differentially regulated metabolite features between two groups. Employing these two tests allows identification of metabolites that differ in intensity between groups. These differentially

280 expressed metabolites are then subjected to pathway analysis. Pathways are determined using MetaboAnalyst's MS Peaks to Pathways feature with the mummichog algorithm. This allows for metabolite compounds identified from the statistical tests described to be associated with biological pathways and for prediction of networks of functional cellular activity. All significance measured were assessed either with the a

285 priori significance level of 0.05 or for multiple comparisons with a false discovery rate (FDR) - corrected significance level of 0.05 .

\section{Results}

290 The goals of this study were to (1) compare the metabolomes of isolated cortical bone, isolated bone marrow, and whole cortical bone of the mouse humerus, (2) evaluate and determine if sex differences exist in the cortical bone metabolome, and (3) assess if metabolic differences are associated with bone material properties (i.e., strength).

295 3.1 The metabolome is distinct for isolated cortical bone, bone marrow, and whole bone.

We first tested whether metabolomic profiles are distinct for isolated cortical bone, bone marrow, and whole bone without marrow removed. Unsupervised and supervised 
300 multivariate statistical analyses, HCA, PCA, and PLS-DA, were utilized to gauge and compare the metabolome of these three tissues. Global metabolomic profiles of bone marrow, isolated cortical bone tissue, and whole cortical bone are substantially different (Figure 2A-C). HCA, an unsupervised method, demonstrates perfect clustering of samples within their respective cohorts (Figure 2A). Further, there is clear separation between the metabolomes of the three cohorts upon both PCA and PLS-DA (Figure 2B,C).

Additionally, there were 2,178 metabolite features that were significantly different between groups using ANOVA. Further, 1,120 metabolite features that differed between 310 the three experimental groups with p-value less than 0.0001 were detected (Figure 2D). In depth analysis revealed metabolite features unique to isolated cortical bone and bone marrow.

Unsupervised clustering of the median intensity for each metabolite within cohort 315 summarizes the major differences between cohorts (Figure 2E). Pathway analysis revealed metabolic pathways unique to bone marrow included steroid hormone biosynthesis, amino acid metabolism (phenylalanine, tyrosine, tryptophan, lysine), vitamin metabolism (biotin metabolism), and purine metabolism. Additionally, heatmap analysis identified that metabolic pathways unique to cortical bone, whether isolated

320 and whole, included amino acid metabolism (cysteine, methionine, histidine, alanine), lipid metabolism (fatty acid elongation, glycosphingolipid metabolism, GPI-anchor biosynthesis, linoleic acid metabolism), electron-transport metabolism (ubiquinone metabolism), and the pentose phosphate pathway (Table 1).

\subsection{Cortical bone metabolism is sexually dimorphic.}

When comparing global metabolomic profiles of isolated cortical bone tissue from male and female mice, a total of 2,129 distinct metabolite features were co-detected. First, the metabolites detected across all male and female isolated cortical bone were

330 analyzed (Figure 3). To visualize differences between experimental groups, HCA was applied, showing that males and females cluster separately with the exception of one male mouse (Figure 3A). We then utilized PCA to analyze the overall variation in the dataset between males and females. Principal component 1 accounts for $24 \%$ of the variation in the dataset (i.e., about 500x greater than expected from random data). This,

335 in tandem with the number of features detected, demonstrate that the metabolome for isolated cortical bone from males and females is different (Figure 3B). We used PLS-DA to further examine the variation within the dataset and between experimental groups. This supervised analysis displayed complete separation between the metabolomes of male and female mice (Figure 3C).

With this knowledge, VIP scores from PLS-DA analyses were used to identify specific metabolite features that contribute the most to differences between male and females. Of the top 300 metabolite features that contributed to the distinction between groups, the majority (75\%) were upregulated in male mice. Significant pathways that contributed to the separation of groups and are primarily associated with male isolated cortical bone 
included amino acid metabolism (cysteine, methionine, arginine, proline) and central energy metabolism (glycolysis, TCA cycle).

T-test, fold change, and volcano plot analysis were employed to further examine differences in metabolism between male and female derived isolated cortical bone tissue (Figure 3). Based on a priori significant level of 0.05 , student's t-test identified 318 metabolite features and fold change analysis yielded 487 metabolite features that were differentially regulated between groups. Further, volcano plot analysis revealed 126 metabolite features were upregulated amongst female mice and 225 were upregulated amongst male mice (Figure 3D-F).

Numerous metabolic pathways were apparent for male and female isolated cortical bone (Table 1). Specific to male mice, the main metabolic theme detected was amino acid metabolism. Upregulated amino acid metabolism included cysteine, methionine,

360 alanine, aspartate, and glutamate. This metabolic theme was detected and associated with both whole and isolated cortical bone. Therefore, this result was expected. Yet, this metabolic theme was significantly upregulated in males compared to females. Beyond amino acid metabolism, central energy metabolism, including glycolysis and the TCA cycle as well as purine metabolism, were differentially regulated between sexes.

Specific to female isolated cortical bone, the main metabolic theme observed was lipid metabolism. This includes sphingolipid metabolism, GPI-anchor biosynthesis, glycerophospholipid metabolism, and the fatty acid pathways of biosynthesis, degradation, and elongation. Similarly, while lipid metabolism was a metabolic theme 370 detected in whole and isolated cortical bone, lipid associated metabolic pathways listed where significantly upregulated from baseline in female mice compared to males.

Since lipid metabolism was prominent in the female bone metabolome, we sought out to investigate and understand if metabolic upregulation of lipid metabolism corresponds to

375 an upregulation in adiposity in females compared to males. Adipocyte count and number of adipocytes per marrow cavity area were $81 \%(p<0.0001)$ and $83 \%(p<$ 0.0001 ) higher in females compared to males (Figure 4E-F). Mean adipocyte size and marrow cavity area measurements were similar for males and female mice (Figure 4 $C, D)$. Mean adipocyte count and number density were both higher for females than 380 males $(p<0.0001$ and $p<0.0001$, respectively). Therefore, females had both increased bone marrow adiposity as well as increased metabolic signature of lipid metabolism.

\subsection{Whole bone material and mechanical properties of bone differ with sex.}

385 Whole-bone material properties differed by sex (Table 2). Females had higher modulus $(+25 \%, p<0.0001)$, ultimate stress $(+14.4 \%, p<0.0001)$, and yield stress $(+18.5 \%, p$ $=0.001$ ), compared to males. No sex differences were found for either $\mathrm{K}_{\mathrm{c}}$ or toughness from three-point bending (e.g., area under stress-strain curve for three-point bending of unnotched femurs). 


\subsection{Sex differences in bone metabolome are associated with sex differences in bone strength}

In this study, females had higher femur modulus, ultimate stress, and yield stress, in alignment with several previous studies ${ }^{(40-42)}$. Ultimate strength showed clear separation of higher-strength from lower-strength individuals in male mice (coefficient of variation: $7.6 \%$ ) but not for female mice (coefficient of variation: $4.7 \%$ ). Therefore, we investigated whether (1) the metabolomes of high-strength and low-strength male bones differ and (2) if metabolomes are distinct between high and low-strength male groups and high400 strength females.

The strongest and weakest femurs from males and only the strongest female femurs were selected as described (males $= \pm 7 \%$, females $=+5 \%$ relative change from mean values for each sex). To assess if metabolomic profiles were associated with bone 405 strength we used HCA, PCA, and PLS-DA (Figure 5). HCA displays limited separation of isolated cortical bone that differs by strength to find clear differences between isolated cortical bone of mice that differ by strength and sex separate (Figure 5E). PCA also finds differences between samples within their respective cohorts. PC2 and PC3 were analyzed and together account for almost $30 \%$ of the overall variation in the

410 dataset (Figure 5A-C). Next, PLS-DA analysis of all 3 groups clearly displays that the metabolome of male bones that differ by strength and high-strength female femurs are metabolically distinct from each other (Figure 5D). Female high-strength femurs were stronger than all male bone and was distinguished from high and low strength males in this PLS-DA analysis.

To find metabolic pathways and features unique to each strength group, median metabolite intensities from each group were subjected to HCA and visualized by heatmap (Figure 5F). All analyses combined found that strong female femurs are associated with pathways including terpenoid backbone biosynthesis, and xenobiotic

420 metabolism by cytochrome P450. Conversely, metabolic themes unique to strong male femurs included purine and pyrimidine metabolism, beta-alanine metabolism, and aminoacyl tRNA biosynthesis. Metabolic pathways shared by males and females with stronger bones included tryptophan and porphyrin metabolism. Finally, the metabolome of males with weaker femurs included the pentose phosphate pathway, pantothenate

425 and CoA biosynthesis, and phosphatidylinositol signaling system. These data show that differences in bone strength are associated with substantial differences in metabolomic profiles of isolated cortical bone.

\section{Discussion}

Bone tissue is modeled and remodeled using the metabolic pathways of bone cells and therefore the bone metabolome may provide fundamental data on sex differences that exist in bone quality. Metabolomic assessment is has been used in other areas of orthopedic research. In particular, metabolomic analyses have been used to assess 435 tissues such as chondrocytes ${ }^{(27,35,36,43,44)}$, synovial fluid ${ }^{(20-25,33)}$, urine ${ }^{(31,32)}$, serum ${ }^{(26,45)}$, and subchondral bone ${ }^{(30)}$. These metabolomic studies contribute to advancing the 
understanding of cellular metabolism during homeostasis and in the presence of injury and disease. Metabolomic profiling has also been applied in search of biomarkers and drug targets for diseases like osteoarthritis ${ }^{(25,33)}$ and rheumatoid arthritis ${ }^{(20,24,34)}$. However, metabolomic analyses are seldom applied to bone tissue and key questions remain unanswered about the dependence of these profiles on sex.

Our first observation is that the metabolomic profiles of isolated cortical bone, bone marrow, and whole bone of the humerus are clearly distinct. Metabolic themes unique to bone marrow included steroid metabolism, vitamin metabolism, and purine metabolism. A metabolic theme shared for all three tissues was amino acid metabolism. However, different amino acids were elevated in each tissue. Phenylalanine, tryptophan, tyrosine, and lysine metabolism were unique to bone marrow. Commonly, phenylalanine, tryptophan, and tyrosine biosynthesis are considered together in metabolic

450 assessments and often feed into various energy pathways including glycolysis and the TCA cycle.

Pathways distinct to isolated cortical bone and whole bone, but not marrow, included cysteine, methionine, histidine, and beta-alanine. Cysteine, along with other glucogenic 455 amino acids, can be used as an energy source by conversion into glucose. Further, homocysteine, a homologue of cysteine, has been associated with bone turnover and low bone mass ${ }^{(46)}$. Methionine is an essential amino acid that plays a large role in several metabolic processes including nucleotide synthesis. Previous results show that methionine restriction has negative impacts on bone density and the innate immune

460 system ${ }^{(14)}$. Previous studies also detected elevated levels of histidine in orthopedic tissues, like synovial fluid and cartilage, in response to mechanical stimulation and osteoarthritis ${ }^{(47,48)}$. Beta-alanine was elevated in synovial fluid, serum, and subchondral bone in osteoarthritis animal models $\mathbf{s}^{(21,26,28,30,49)}$.

465 Our results agree with previous work that bone material properties are sexually dimorphic ${ }^{(1-4,12,18,40-42,50)}$. Changes in amino acid metabolism were detected in all three tissues of interest and in both sexes. However, this metabolic theme was significantly upregulated in isolated cortical bone from males compared to females. The amino acids that were upregulated in males included alanine, aspartate, glutamate, cysteine, and

470 methionine. Alanine is generated from pyruvate, therefore, is closely linked to glycolysis, the TCA cycle. Biochemically, alanine often aids in the recycling of carbon backbones in places such as skeletal muscle and the liver. Previous studies show that there is a relationship between alanine aminotransferases and bone mineral density, but uncertainty remains about the role of alanine in bone health ${ }^{(49)}$. Glutamate is an

475 excitatory neurotransmitter, and there is a growing body of evidence of a regulatory role for glutamate in osteoblast and osteoclast differentiation, as well as bone homeostasis ${ }^{(51-55)}$.

Lipid metabolism was a common metabolic theme in both isolated and whole cortical 480 bone. Furthermore, lipid metabolism was greatly upregulated in female mice compared to males (Table 1). The metabolism of lipids is essential for energy production and balance, membrane dynamics, and signaling ${ }^{(56)}$. Further, fatty acids and other lipids are 
transported systemically via chylomicrons and commonly cleared by the liver and bone. After the liver, the femur diaphysis is the second most active organ for chylomicron reuptake supporting the idea that normal osteoblast proliferation is fueled by serum lipoproteins ${ }^{(57,58)}$. This is consistent with the canonical role of bone's importance in fatty acid clearance for energy purposes ${ }^{(12,59)}$. When skeletal cells experience low lipid levels, osteogenesis is negatively affected as osteoblasts greatly depend on fatty acid oxidation and degradation ${ }^{(60)}$. In this study, female mice showed upregulation of lipid-

490 associated metabolic pathways. Therefore, females may potentially utilize increased fatty acid clearance than males to meet energy demands.

Female mice are reported in some studies to have stronger or stiffer bones than males $^{(42,50)}$. Yet, no study to date has assessed the presence, or absence, of sexual 495 dimorphism in the metabolomic profiles of cortical bone. Furthermore, it was not known if the bone metabolome is associated with bone material properties such as strength. We compared the metabolomes of isolated humerus cortical bone for females and males with higher or lower strength femurs. In total, we found 12 significant metabolic pathways and 51 metabolites that differ between groups (Table 1). Among these 12

500 pathways, the bone metabolome of male mice with higher ultimate stress includes nucleotide metabolism. In contrast, the metabolomes of both male and female mice with higher ultimate stress shared pathways including tryptophan and porphyrin metabolism. Further, females with higher ultimate stress included metabolites representing terpenoid backbone biosynthesis, primary bile acid biosynthesis, and xenobiotic metabolism.

505 Finally, males with lower ultimate stress showed pathways related to vitamin, energy, and phosphatidylinositol signaling metabolism.

Tryptophan metabolism was a common theme associated with higher ultimate stress for both male and female mice. Previous studies found this metabolic pathway and its 510 metabolites to play a role in the regulation of bone remodeling ${ }^{(61)}$. Tryptophan is an amino acid that must be provided in the diet and is a precursor to serotonin, melatonin, and kynurenine ${ }^{(62-64)}$. Tryptophan prominently affects bone formation by stimulating proliferation and differentiation of bone cells and bone marrow mesenchymal stem cells ${ }^{(65)}$.

Specific to males with higher ultimate strength, nucleotide metabolism was a common theme. This theme included purine and pyrimidine metabolism as well as aminoacyltRNA biosynthesis. Purine and pyrimidine metabolism are important pathways for DNA and amino acid synthesis ${ }^{(66)}$. Upregulation of these pathways in strong male bones may

520 relate to an increase in cellular demand of complex molecules such as DNA, RNA, and amino acids. Both purine and pyrimidine are derived from the pentose phosphate pathway, which was upregulated in male mice with low ultimate strength. Finally, a metabolic pathway unique to males with weaker bones was phosphatidylinositol (PI) signaling system. This system contributes to and plays a role in calcium signaling ${ }^{(67)}$.

525 Osteoclasts and osteocytes greatly rely on intracellular calcium signaling for differentiation and bone resorption ${ }^{(68)}$. Bone strength is influenced by bone tissue maturity ${ }^{(69,70)}$ and therefore the activity of remodeling bone cells. The increased tryptophan metabolism in strong males and females increased nucleotide metabolism 
530 these pathways are related to bone tissue remodeling. However, additional studies are needed to detail the association between bone remodeling and the metabolome.

There are important limitations to this study. First, the humerus was utilized for metabolomic analysis; therefore, the metabolism of other bones like the femur may

535 differ. Second, while male C57BI/6J mice were utilized in this strength-metabolomics experiments, only female C57Bl/6J mice were used to assess metabolic differences between whole bone, isolated bone, and bone marrow. Third, metabolomic analyses were conducted using the humerus while 3-point bending was performed on the femur. This is a necessary limitation to preserve the integrity of metabolites in tissues

540 subjected to metabolomic analyses.

In summary, these data suggest that (1) the metabolome of musculoskeletal system related tissues are distinct, (2) the metabolome of isolated cortical bone is sexually dimorphic, with 8 pathways represented in males and 4 pathways in females, and (3) 545 metabolism is distinct between mice with differing bone strength. Together, these data demonstrate that metabolomics assesses and underpins metabolic themes occurring in different tissues, males and females, and in the bone that differs in strength.

\section{Acknowledgements}

550 We thank the Montana State University Mass Spectrometry Facility and Dr. Katie Steward for assisting in LC-MS analysis. Funding for the Proteomics, Metabolomics and Mass Spectrometry Facility used in this publication was made possible in part by the MJ Murdock Charitable Trust, the National Institute of General Medical Sciences of the National Institutes of Health under Award Numbers P20GM103474 and S100D28650,

555 and the MSU Office of Research, Economic Development and Graduate Education. Additionally, assistance from Maria Jerome at the Montana State University Histology Core Facility, and Heidi Smith and Markus Dieserat the Center for Biofilm Engineering at Montana State University in histological preparation, imaging, and analysis is gratefully acknowledged. We acknowledge the Center for Advanced Orthopaedic

560 Research for microCT analyses. Finally, we thank Maya Moody, Leah Davidson, Kenna Brown, and Priyanka Brahmachary for assisting with tissue harvests. Funding was provided by the National Science Foundation (CMMI 1554708) and the National Institutes of Health (NIAMS R01AR073964, NIGMS P20GM103474).

\section{Conflict of Interest}

The authors have no conflicts of interest to disclose.

\section{Author contributions}

HDW performed dissections, extracted metabolites, analyzed data, and drafted the

570 manuscript. GV performed dissections, bone flexural testing, and analyzed data. STW supplied study mice. BB assisted in analyzing data. $\mathrm{CMH}$ designed experiments and analyzed data. RKJ designed experiments and analyzed data. All authors have read and revised the manuscript. 


\section{References}

1. Sherk VD, Heveran CM, Foright RM, Johnson GC, Presby DM, Ferguson VL, et al. Sex differences in the effect of diet, obesity, and exercise on bone quality and fracture toughness. Bone. Apr 2021;145:115840. Epub 2021/01/09.

2. Willinghamm MD, Brodt MD, Lee KL, Stephens AL, Ye J, Silva MJ. Age-related changes in bone structure and strength in female and male BALB/c mice. Calcif Tissue Int. Jun 2010;86(6):470-83. Epub 2010/04/21.

3. Ward WE, Kim S, Robert Bruce W. A western-style diet reduces bone mass and biomechanical bone strength to a greater extent in male compared with female rats during development. Br J Nutr. Sep 2003;90(3):589-95. Epub 2003/09/18.

4. Creecy A, Uppuganti S, Girard MR, Schlunk SG, Amah C, Granke M, et al. The agerelated decrease in material properties of $B A L B / c$ mouse long bones involves alterations to the extracellular matrix. Bone. Jan 2020;130:115126. Epub 2019/11/05.

5905 5eeman E. Bone quality: the material and structural basis of bone strength. J Bone Miner Metab. 2008;26(1):1-8. Epub 2007/12/21.

6. Hernandez CJ, Keaveny TM. A biomechanical perspective on bone quality. Bone. Dec 2006;39(6):1173-81. Epub 2006/08/01.

7. Datta HK, Ng WF, Walker JA, Tuck SP, Varanasi SS. The cell biology of bone metabolism. J Clin Pathol. May 2008;61(5):577-87. Epub 2008/04/29.

8. Alliston T. Biological regulation of bone quality. Curr Osteoporos Rep. Sep 2014;12(3):366-75. Epub 2014/06/05.

9. Motyl KJ, Guntur AR, Carvalho AL, Rosen CJ. Energy Metabolism of Bone. Toxicol Pathol. Oct 2017;45(7):887-93. Epub 2017/11/04.

600 10. Karthik V, Guntur AR. Energy Metabolism of Osteocytes. Curr Osteoporos Rep. Jun 12 2021. Epub 2021/06/13.

11. Lee WC, Guntur AR, Long F, Rosen CJ. Energy Metabolism of the Osteoblast: Implications for Osteoporosis. Endocr Rev. Jun 1 2017;38(3):255-66. Epub 2017/05/05.

12. Kim SP, Li Z, Zoch ML, Frey JL, Bowman CE, Kushwaha P, et al. Fatty acid oxidation by the osteoblast is required for normal bone acquisition in a sex- and diet-dependent manner. JCI Insight. Aug 17 2017;2(16). Epub 2017/08/18.

13. Shum LC, White NS, Nadtochiy SM, Bentley KL, Brookes PS, Jonason JH, et al. Cyclophilin D Knock-Out Mice Show Enhanced Resistance to Osteoporosis and to Metabolic Changes Observed in Aging Bone. PLoS One. 2016;11(5):e0155709. Epub $610 \quad$ 2016/05/18. 
14. Li M, Zhai L, Wei W, Dong J. Effect of Methionine Restriction on Bone Density and NK Cell Activity. Biomed Res Int. 2016;2016:3571810. Epub 2016/11/25.

15. Meakin LB, Galea GL, Sugiyama T, Lanyon LE, Price JS. Age-related impairment of bones' adaptive response to loading in mice is associated with sex-related deficiencies in osteoblasts but no change in osteocytes. J Bone Miner Res. Aug 2014;29(8):1859-71. Epub 2014/03/20.

16. Galea GL, Meakin LB, Harris MA, Delisser PJ, Lanyon LE, Harris SE, et al. Old age and the associated impairment of bones' adaptation to loading are associated with transcriptomic changes in cellular metabolism, cell-matrix interactions and the cell cycle. Gene. Jan 30 2017;599:36-52. Epub 2016/11/15.

17. Sherk VD, Rosen CJ. Senescent and apoptotic osteocytes and aging: Exercise to the rescue? Bone. Apr 2019;121:255-8. Epub 2019/02/09.

18. Liu Z, Solesio ME, Schaffler MB, Frikha-Benayed D, Rosen CJ, Werner H, et al. Mitochondrial Function Is Compromised in Cortical Bone Osteocytes of Long-Lived Growth Hormone Receptor Null Mice. J Bone Miner Res. Jan 2019;34(1):106-22. Epub 2018/09/15.

19. Jewett MC, Hofmann G, Nielsen J. Fungal metabolite analysis in genomics and phenomics. Curr Opin Biotechnol. Apr 2006;17(2):191-7. Epub 2006/02/21.

20. Kim S, Hwang J, Xuan J, Jung YH, Cha HS, Kim KH. Global metabolite profiling of synovial fluid for the specific diagnosis of rheumatoid arthritis from other inflammatory arthritis. PLoS One. 2014;9(6):e97501. Epub 2014/06/03.

21. Hugle T, Kovacs H, Heijnen IA, Daikeler T, Baisch U, Hicks JM, et al. Synovial fluid metabolomics in different forms of arthritis assessed by nuclear magnetic resonance spectroscopy. Clin Exp Rheumatol. Mar-Apr 2012;30(2):240-5. Epub 2012/03/14.

635 22. Hahn AK, Wallace CW, Welhaven HD, Brooks E, McAlpine M, Christiansen BA, et al. The microbiome mediates epiphyseal bone loss and metabolomic changes after acute joint trauma in mice. Osteoarthritis Cartilage. Jun 2021;29(6):882-93. Epub 2021/03/22.

23. Carlson AK, Rawle RA, Wallace CW, Brooks EG, Adams E, Greenwood MC, et al. Characterization of synovial fluid metabolomic phenotypes of cartilage morphological changes associated with osteoarthritis. Osteoarthritis Cartilage. Aug 2019;27(8):117484. Epub 2019/04/28.

24. Carlson AK, Rawle RA, Wallace CW, Adams E, Greenwood MC, Bothner B, et al. Global metabolomic profiling of human synovial fluid for rheumatoid arthritis biomarkers. Clin Exp Rheumatol. May-Jun 2019;37(3):393-9. Epub 2019/01/09.

645 25. Carlson AK, Rawle RA, Adams E, Greenwood MC, Bothner B, June RK. Application of global metabolomic profiling of synovial fluid for osteoarthritis biomarkers. Biochem Biophys Res Commun. May 5 2018;499(2):182-8. Epub 2018/03/20. 
26. Zhang W, Sun G, Likhodii S, Liu M, Aref-Eshghi E, Harper PE, et al. Metabolomic analysis of human plasma reveals that arginine is depleted in knee osteoarthritis patients. Osteoarthritis Cartilage. May 2016;24(5):827-34. Epub 2015/12/29.

27. Zhang W, Likhodii S, Zhang Y, Aref-Eshghi E, Harper PE, Randell E, et al. Classification of osteoarthritis phenotypes by metabolomics analysis. BMJ Open. Nov 19 2014;4(11):e006286. Epub 2014/11/21.

28. Maher AD, Coles C, White J, Bateman JF, Fuller ES, Burkhardt D, et al. 1H NMR spectroscopy of serum reveals unique metabolic fingerprints associated with subtypes of surgically induced osteoarthritis in sheep. J Proteome Res. Aug 3 2012;11(8):4261-8. Epub 2012/07/13.

29. Zhao H, Li X, Zhang D, Chen H, Chao Y, Wu K, et al. Integrative Bone MetabolomicsLipidomics Strategy for Pathological Mechanism of Postmenopausal Osteoporosis Mouse Model. Sci Rep. Nov 7 2018;8(1):16456. Epub 2018/11/09.

30. Yang G, Zhang H, Chen T, Zhu W, Ding S, Xu K, et al. Metabolic analysis of osteoarthritis subchondral bone based on UPLC/Q-TOF-MS. Anal Bioanal Chem. Jun 2016;408(16):4275-86. Epub 2016/04/15.

31. Loeser RF, Pathmasiri W, Sumner SJ, McRitchie S, Beavers D, Saxena P, et al. Association of urinary metabolites with radiographic progression of knee osteoarthritis in overweight and obese adults: an exploratory study. Osteoarthritis Cartilage. Aug 2016;24(8):1479-86. Epub 2016/03/26.

32. Lamers RJ, van Nesselrooij JH, Kraus VB, Jordan JM, Renner JB, Dragomir AD, et al. Identification of an urinary metabolite profile associated with osteoarthritis. Osteoarthritis Cartilage. Sep 2005;13(9):762-8. Epub 2005/06/14.

33. Kim S, Hwang J, Kim J, Ahn JK, Cha HS, Kim KH. Metabolite profiles of synovial fluid change with the radiographic severity of knee osteoarthritis. Joint Bone Spine. Oct 2017;84(5):605-10. Epub 2016/07/28.

34. Guma M, Tiziani S, Firestein GS. Metabolomics in rheumatic diseases: desperately seeking biomarkers. Nat Rev Rheumatol. May 2016;12(5):269-81. Epub 2016/03/05.

35. Zignego DL, Hilmer JK, June RK. Mechanotransduction in primary human osteoarthritic chondrocytes is mediated by metabolism of energy, lipids, and amino acids. J Biomech. Dec 16 2015;48(16):4253-61. Epub 2015/11/18.

36. McCutchen CN, Zignego DL, June RK. Metabolic responses induced by compression of chondrocytes in variable-stiffness microenvironments. J Biomech. Nov 7 2017;64:49-58. Epub 2017/10/08.

37. Bouxsein ML, Boyd SK, Christiansen BA, Guldberg RE, Jepsen KJ, Muller R. Guidelines for assessment of bone microstructure in rodents using micro-computed tomography. J Bone Miner Res. Jul 2010;25(7):1468-86. Epub 2010/06/10.

685 38. Turner $\mathrm{CH}$, Burr DB. Basic biomechanical measurements of bone: a tutorial. Bone. JulAug 1993;14(4):595-608. Epub 1993/07/01. 
39. Ritchie RO, Koester KJ, lonova S, Yao W, Lane NE, Ager JW, 3rd. Measurement of the toughness of bone: a tutorial with special reference to small animal studies. Bone. Nov 2008;43(5):798-812. Epub 2008/07/24.

690 40. Vegger JB, Bruel A, Brent MB, Thomsen JS. Disuse osteopenia induced by botulinum toxin is similar in skeletally mature young and aged female C57BL/6J mice. J Bone Miner Metab. Mar 2018;36(2):170-9. Epub 2017/04/04.

41. Mumtaz H, Dallas M, Begonia M, Lara-Castillo N, Scott JM, Johnson ML, et al. Agerelated and sex-specific effects on architectural properties and biomechanical response of the C57BL/6N mouse femur, tibia and ulna. Bone Rep. Jun 2020;12:100266. Epub 2020/05/19.

42. Behrendt AK, Kuhla A, Osterberg A, Polley C, Herlyn P, Fischer DC, et al. Dietary Restriction-Induced Alterations in Bone Phenotype: Effects of Lifelong Versus ShortTerm Caloric Restriction on Femoral and Vertebral Bone in C57BL/6 Mice. J Bone Miner Res. Apr 2016;31(4):852-63. Epub 2015/11/18.

43. Salinas D, Mumey BM, June RK. Physiological dynamic compression regulates central energy metabolism in primary human chondrocytes. Biomech Model Mechanobiol. Feb 2019;18(1):69-77. Epub 2018/08/12.

44. Jutila AA, Zignego DL, Hwang BK, Hilmer JK, Hamerly T, Minor CA, et al. Candidate mediators of chondrocyte mechanotransduction via targeted and untargeted metabolomic measurements. Arch Biochem Biophys. Mar 1 2014;545:116-23. Epub $2014 / 01 / 21$.

45. Bar N, Korem T, Weissbrod O, Zeevi D, Rothschild D, Leviatan S, et al. A reference map of potential determinants for the human serum metabolome. Nature. Dec 2020;588(7836):135-40. Epub 2020/11/13.

46. Baines M, Kredan MB, Davison A, Higgins G, West C, Fraser WD, et al. The association between cysteine, bone turnover, and low bone mass. Calcif Tissue Int. Dec 2007;81(6):450-4. Epub 2007/12/07.

47. Tetlow LC, Woolley DE. Histamine, histamine receptors ( $\mathrm{H} 1$ and $\mathrm{H} 2)$, and histidine decarboxylase expression by chondrocytes of osteoarthritic cartilage: an immunohistochemical study. Rheumatol Int. Dec 2005;26(2):173-8. Epub 2005/06/30.

48. Tetlow LC, Woolley DE. Histamine stimulates the proliferation of human articular chondrocytes in vitro and is expressed by chondrocytes in osteoarthritic cartilage. Ann Rheum Dis. Oct 2003;62(10):991-4. Epub 2003/09/16.

720 49. Xia MF, Lin HD, Yan HM, Bian H, Chang XX, Zhang LS, et al. The association of liver fat content and serum alanine aminotransferase with bone mineral density in middle-aged and elderly Chinese men and postmenopausal women. J Transl Med. Jan 13 2016;14:11. Epub 2016/01/23.

50. Glatt V, Canalis E, Stadmeyer L, Bouxsein ML. Age-related changes in trabecular architecture differ in female and male C57BL/6J mice. J Bone Miner Res. Aug 2007;22(8):1197-207. Epub 2007/05/10. 
51. Skerry TM. The role of glutamate in the regulation of bone mass and architecture. J Musculoskelet Neuronal Interact. Apr-Jun 2008;8(2):166-73. Epub 2008/07/16.

52. Mason DJ, Suva LJ, Genever PG, Patton AJ, Steuckle S, Hillam RA, et al. Mechanically regulated expression of a neural glutamate transporter in bone: a role for excitatory amino acids as osteotropic agents? Bone. Mar 1997;20(3):199-205. Epub 1997/03/01.

53. Forrest CM, Mackay GM, Oxford L, Stoy N, Stone TW, Darlington LG. Kynurenine pathway metabolism in patients with osteoporosis after 2 years of drug treatment. Clin Exp Pharmacol Physiol. Nov 2006;33(11):1078-87. Epub 2006/10/18.

735 54. Fatokun AA, Stone TW, Smith RA. Hydrogen peroxide-induced oxidative stress in MC3T3-E1 cells: The effects of glutamate and protection by purines. Bone. Sep 2006;39(3):542-51. Epub 2006/04/18.

55. Chenu C, Serre CM, Raynal C, Burt-Pichat B, Delmas PD. Glutamate receptors are expressed by bone cells and are involved in bone resorption. Bone. Apr 1998;22(4):2959. Epub 1998/04/29.

56. Kushwaha P, Wolfgang MJ, Riddle RC. Fatty acid metabolism by the osteoblast. Bone. Oct 2018;115:8-14. Epub 2017/09/03.

57. Niemeier A, Niedzielska D, Secer R, Schilling A, Merkel M, Enrich C, et al. Uptake of postprandial lipoproteins into bone in vivo: impact on osteoblast function. Bone. Aug 2008;43(2):230-7. Epub 2008/06/10.

58. Catherwood BD, Addison J, Chapman G, Contreras S, Lorang M. Growth of rat osteoblast-like cells in a lipid-enriched culture medium and regulation of function by parathyroid hormone and 1,25-dihydroxyvitamin D. J Bone Miner Res. Aug 1988;3(4):431-8. Epub 1988/08/01.

750 59. Bartelt A, Koehne T, Todter K, Reimer R, Muller B, Behler-Janbeck F, et al. Quantification of Bone Fatty Acid Metabolism and Its Regulation by Adipocyte Lipoprotein Lipase. Int J Mol Sci. Jun 13 2017;18(6). Epub 2017/06/14.

60. van Gastel N, Stegen S, Eelen G, Schoors S, Carlier A, Daniels VW, et al. Lipid availability determines fate of skeletal progenitor cells via SOX9. Nature. Mar 2020;579(7797):111-7. Epub 2020/02/28.

61. Michalowska M, Znorko B, Kaminski T, Oksztulska-Kolanek E, Pawlak D. New insights into tryptophan and its metabolites in the regulation of bone metabolism. J Physiol Pharmacol. Dec 2015;66(6):779-91. Epub 2016/01/16.

62. Sainio EL, Pulkki K, Young SN. L-Tryptophan: Biochemical, nutritional and pharmacological aspects. Amino Acids. Mar 1996;10(1):21-47. Epub 1996/03/01.

63. Le Floc'h N, Otten W, Merlot E. Tryptophan metabolism, from nutrition to potential therapeutic applications. Amino Acids. Nov 2011;41(5):1195-205. Epub 2010/09/28. 
64. Hopkins FG, Cole SW. A contribution to the chemistry of proteids: Part I. A preliminary study of a hitherto undescribed product of tryptic digestion. J Physiol. Dec 23 1901;27(45):418-28. Epub 1901/12/23.

65. El Refaey M, Watkins CP, Kennedy EJ, Chang A, Zhong Q, Ding KH, et al. Oxidation of the aromatic amino acids tryptophan and tyrosine disrupts their anabolic effects on bone marrow mesenchymal stem cells. Mol Cell Endocrinol. Jul 15 2015;410:87-96. Epub 2015/02/01.

770 66. Siddiqui A, Ceppi P. A non-proliferative role of pyrimidine metabolism in cancer. Mol Metab. May 2020;35:100962. Epub 2020/04/04.

67. MacNicol M, Jefferson AB, Schulman H. Ca2+/calmodulin kinase is activated by the phosphatidylinositol signaling pathway and becomes Ca2(+)-independent in PC12 cells. J Biol Chem. Oct 25 1990;265(30):18055-8. Epub 1990/10/25.

775 68. Kajiya H. Calcium signaling in osteoclast differentiation and bone resorption. Adv Exp Med Biol. 2012;740:917-32. Epub 2012/03/29.

69. Seeman E. Bone modeling and remodeling. Crit Rev Eukaryot Gene Expr. 2009;19(3):219-33. Epub 2009/11/04.

70. Sambrook P, Kelly P, Eisman J. Bone mass and ageing. Baillieres Clin Rheumatol. Oct 1993;7(3):445-57. Epub 1993/10/01. 


\section{Figures and Tables}

Table 1. A) Distinct metabolic pathways associated with humerus-derived isolated

785 cortical bone, whole bone, and bone marrow from male and female C57Bl/6 mice. B)

Metabolic pathways distinct to females and males for the isolated cortical humerus. C) Metabolic pathways distinct to high strength males, high strength females, and low strength males. Pathways listed have an false discovery rate-corrected significance level $<0.05$.

\begin{tabular}{|c|c|c|c|}
\hline \multicolumn{4}{|l|}{ A) Musculoskeletal tissue associated pathways } \\
\hline \begin{tabular}{|c|} 
Metabolic Pathway \\
\end{tabular} & Pathway Total & Hits & Tissue \\
\hline Glycosaminoglycan degradation & 21 & 13 & Whole Bone \\
\hline Pentose phosphate pathway & 22 & 5 & Whole Bone \\
\hline Cysteine and methionine metabolism & 33 & 6 & Whole Bone \\
\hline Fatty acid elongation & 30 & 4 & Whole Bone \\
\hline Histidine metabolism & 16 & 7 & Whole Bone \\
\hline Ubiquinone and other terpenoid-quinone biosynthesis & 9 & 6 & Isolated Cortical Bone \\
\hline Mannose type O-glycan biosynthesis & 16 & 6 & Isolated Cortical Bone \\
\hline Linoleic acid metabolism & 4 & 3 & Isolated Cortical Bone \\
\hline Glycosphingolipid biosynthesis - ganglio series & 21 & 3 & Isolated Cortical Bone \\
\hline Beta-Alanine metabolism & 21 & 9 & Whole + Isolated Bone \\
\hline Glycosylphosphatidylinositol (GPI)-anchor biosynthesis & 11 & 6 & Whole + Isolated Bone \\
\hline Steroid hormone biosynthesis & 77 & 61 & Bone Marrow \\
\hline Phenylalanine, tyrosine and tryptophan biosynthesis & 4 & 2 & Bone Marrow \\
\hline Lysine degradation & 19 & 10 & Bone Marrow \\
\hline Phenylalanine metabolism & 12 & 4 & Bone Marrow \\
\hline Biotin metabolism & 4 & 4 & Bone Marrow \\
\hline Purine metabolism & 66 & 20 & Bone Marrow \\
\hline \multicolumn{4}{|l|}{ B) Sexually dimorphic pathways } \\
\hline Alanine, aspartate and glutamate metabolism & 28 & 4 & Male \\
\hline Cysteine and methionine metabolism & 33 & 4 & Male \\
\hline Purine metabolism & 66 & 7 & Male \\
\hline Glycolysis / Gluconeogenesis & 23 & 3 & Male \\
\hline Citrate cycle (TCA cycle) & 16 & 3 & Male \\
\hline Sphingolipid metabolism & 9 & 2 & Female \\
\hline Glycerophospholipid metabolism & 13 & 1 & Female \\
\hline GPI-anchor biosynthesis & 11 & 3 & Female \\
\hline Fatty acid biosynthesis & 10 & 2 & Female \\
\hline \multicolumn{4}{|l|}{ C) Strength associated pathways } \\
\hline Purine metabolism & 66 & 10 & High Strength Males \\
\hline Porphyrin metabolism & 27 & 6 & High Strength Males \\
\hline Pyrimidine metabolism & 39 & 7 & High Strength Males \\
\hline Tryptophan metabolism & 41 & 7 & High Strength Males \\
\hline beta-Alanine metabolism & 21 & 3 & High Strength Males \\
\hline Aminoacyl-tRNA biosynthesis & 22 & 3 & High Strength Males \\
\hline Terpenoid backbone biosynthesis & 15 & 4 & High Strength Females \\
\hline Metabolism of xenobiotics by cytochrome P450 & 64 & 14 & High Strength Females \\
\hline Tryptophan metabolism & 41 & 7 & High Strength Females \\
\hline Porphyrin metabolism & 27 & 6 & High Strength Females \\
\hline Pentose phosphate pathway & 22 & 2 & Low Strength Males \\
\hline Pantothenate and CoA biosynthesis & 17 & 3 & Low Strength Males \\
\hline Phosphatidylinositol signaling system & 17 & 3 & Low Strength Males \\
\hline
\end{tabular}


Table 2: Femur material properties from 3-point bending. Data are presented as mean \pm standard deviation from the mean.

\begin{tabular}{|l|c|c|}
\hline \multicolumn{1}{|c|}{ Measurement } & Female & Male \\
\hline $\begin{array}{l}\text { Modulus }(\mathrm{GPa}) \\
\mathrm{p}<0.0001\end{array}$ & $7.64 \pm 0.62$ & $5.73 \pm 0.57$ \\
\hline $\begin{array}{l}\text { Ultimate Stress }(\mathrm{MPa}) \\
\mathrm{p}<0.0001\end{array}$ & $162.24 \pm 7.63$ & $138.9 \pm 13.9$ \\
\hline $\begin{array}{l}\text { Yield Stress }(\mathrm{MPa}) \\
\mathrm{p}=0.001\end{array}$ & $119.98 \pm 8.59$ & $97.8 \pm 13.6$ \\
\hline $\begin{array}{l}\text { Toughness }\left(\mathrm{N} / \mathrm{mm}^{2}\right) \\
\mathrm{p}=0.406\end{array}$ & $9.59 \pm 2.08$ & $8.52 \pm 3.37$ \\
\hline $\begin{array}{l}\text { Fracture toughness }(\mathrm{MPa} \sqrt{\mathrm{m}}) \\
\mathrm{p}=0.893\end{array}$ & $4.13 \pm 0.57$ & $4.19 \pm 1.26$ \\
\hline
\end{tabular}


bioRxiv preprint doi: https://doi.org/10.1101/2021.08.06.455423; this version posted Auqust 6, 2021. The copyright holder for this preprint (which was not certified by peer review) is the author/funder, who has granted bioRxiv a license to display the preprint in perpetuity. It is made available under aCC-BY-NC-ND 4.0 International license.

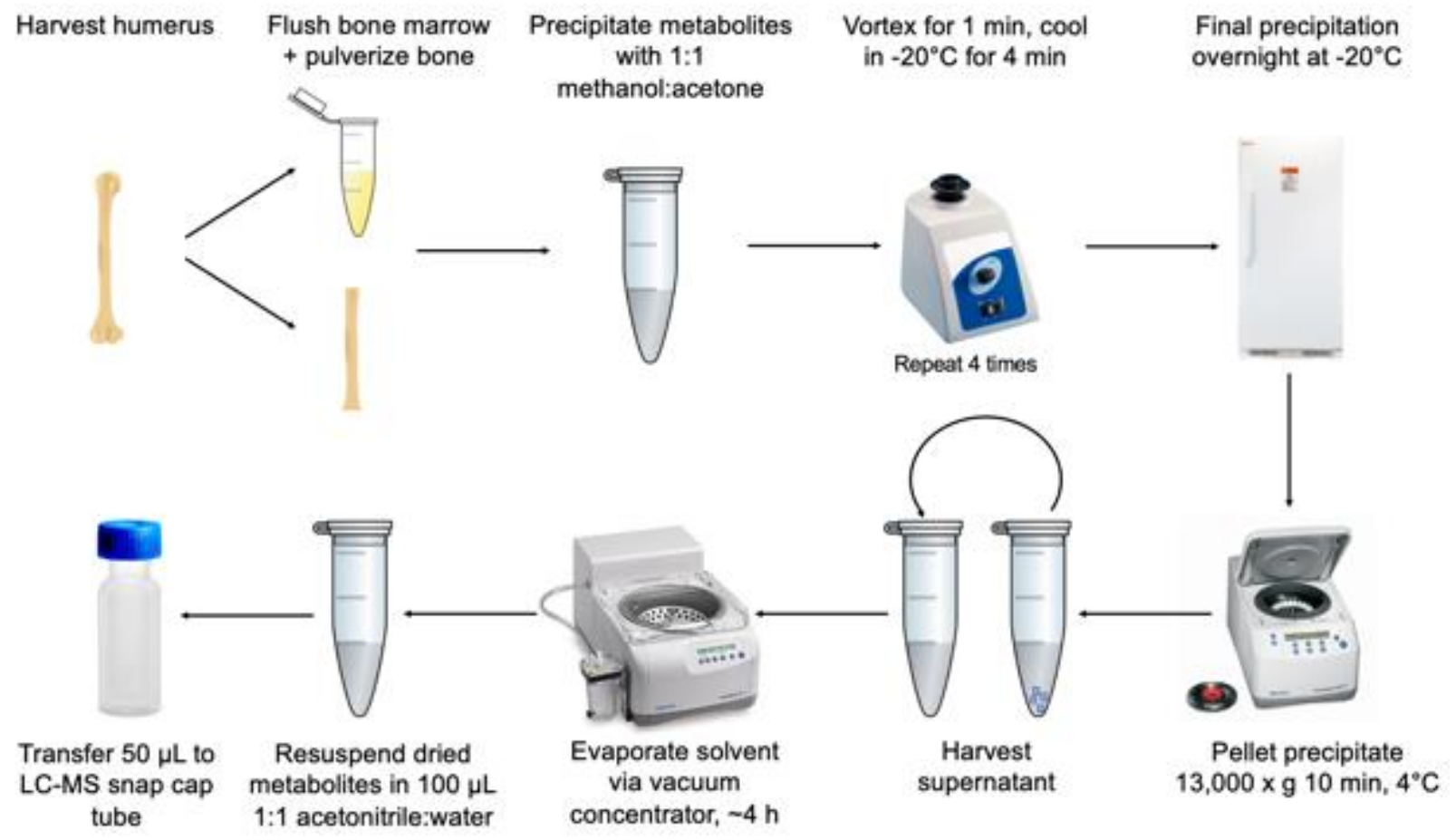

800 Figure 1. Experimental protocol for extracting metabolites from bone and bone marrow. 
A Unsupervised Clustering

B Principal Components

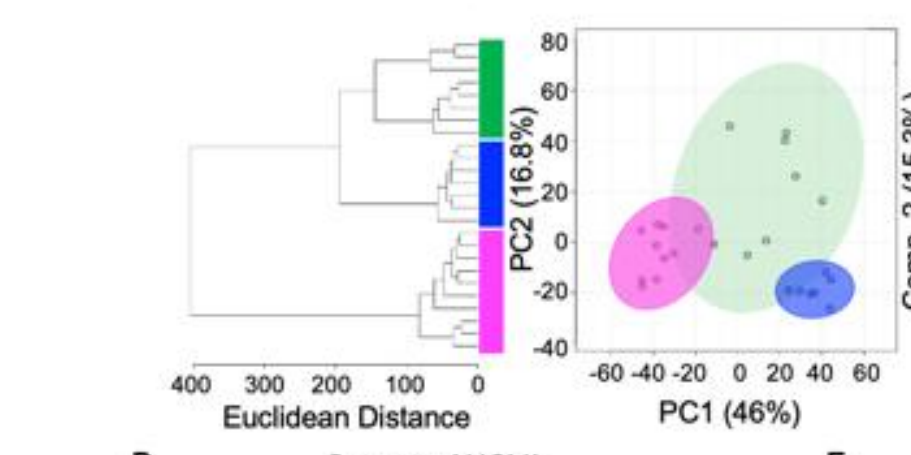

C Partial Least-Squares Discriminant Analysis

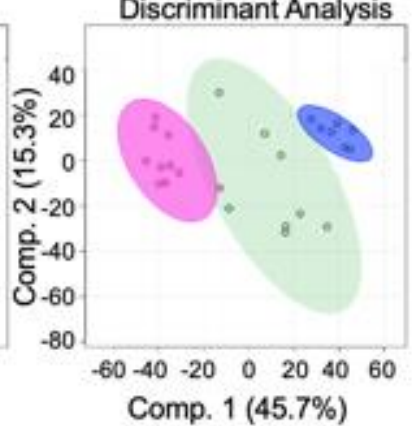

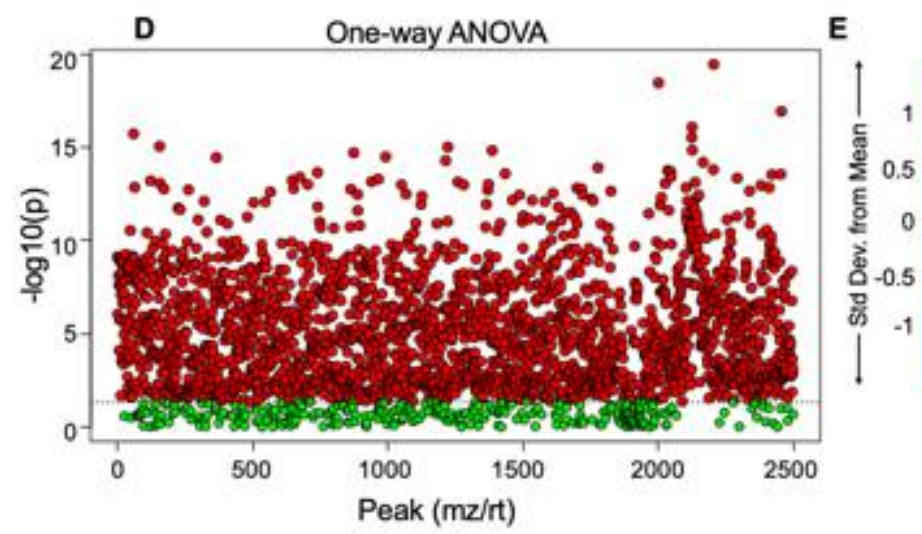

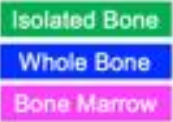

Figure 2. The metabolome of various tissues including whole cortical bone, isolated cortical bone, and bone marrow greatly differ. A total of 2,764 metabolite features were detected across all experimental groups including isolated bone, whole bone, and bone marrow. Features were analyzed using unsupervised (HCA and PCA) and supervised (PLS-DA) statistical methods. (A) Unsupervised HCA visualized by a

810 dendrogram reveals that the metabolome individual tissues cluster together and are distinct from each other. (B) PCA, shown as a scatterplot, displays minimal overlap of clusters. The $x$ axis shows PC1 which accounts for $46 \%$ of the variation in the dataset and the y axis shows PC2 which accounts for $16.8 \%$ of variation. (C) Supervised PLSDA further displays clear separation of groups and further supports the notion that the

815 metabolome of various tissues including isolated bone, whole bone, and bone marrow are unique. Component 1 and 2 combined accounts for $63 \%$ of variation within the dataset. The colors in A-C correspond to experimental groups: green - isolated bone, blue - whole bone, pink - bone marrow. (D) ANOVA analysis identifies over 2,000 statistically significant metabolite that are differentially regulated across tissues. (E)

820 Heatmap analysis reveals that metabolic phenotypes greatly differ between isolated bone, whole bone, and bone marrow. Median intensities were clustered into 3 respective groups via MATLAB to visualize metabolic differences and phenotypes for tissues of interest. 

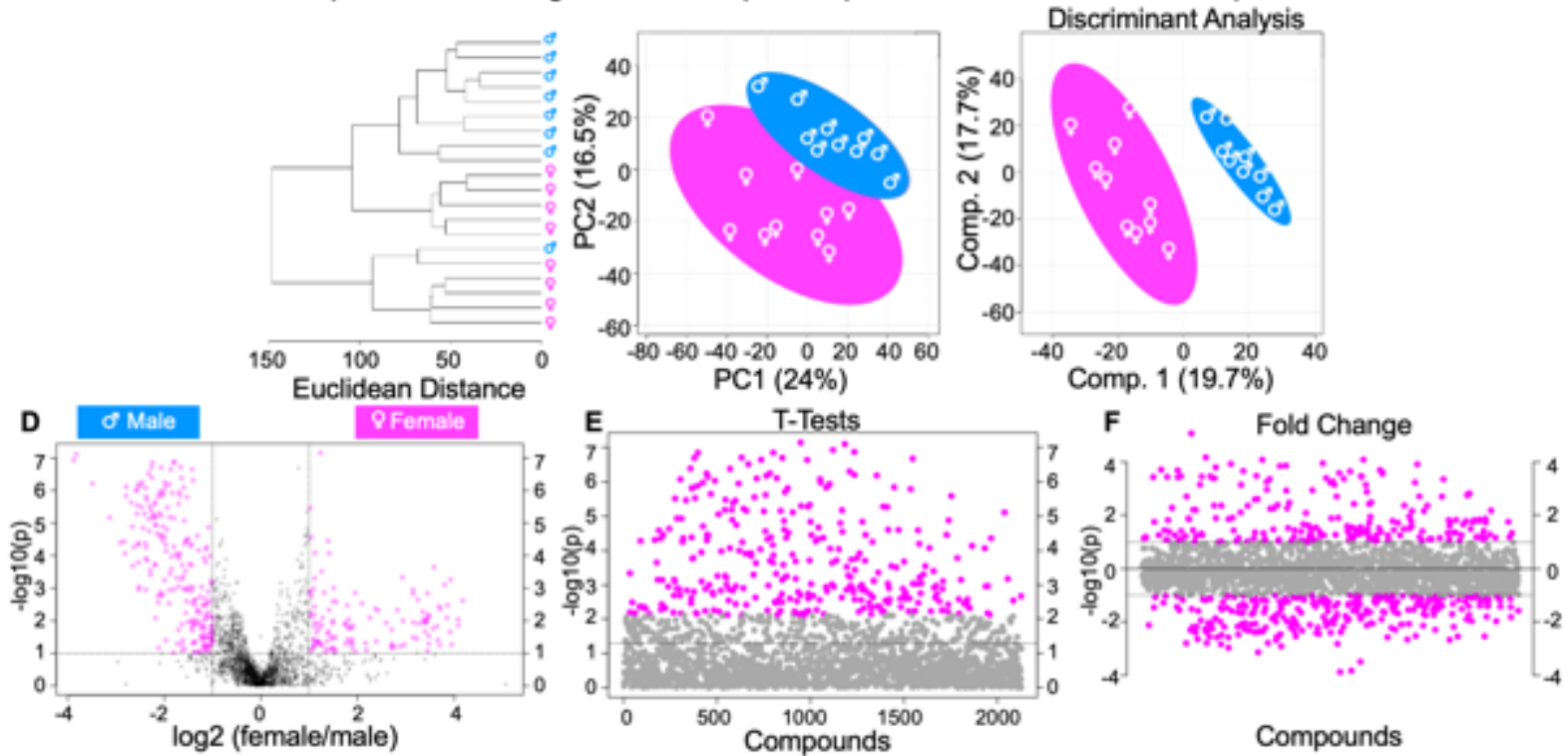

Figure 3. Metabolomic profiles of isolated bone show sexual dimorphism. A total of 2,129 metabolite features were detected and analyzed by both unsupervised hierarchical clustering (HCA) and principal component analysis (PCA) and supervised partial least-squares discriminant analysis (PLS-DA). (A) Unsupervised HCA visualized by a dendrogram displays distinguished clusters between male and female mice, with the exception of one male mouse clustering amongst females. (B) PCA, similar to HCA, displays distinguished clusters with minimal overlap of males and females. PCA is shown as a scatterplot with the first two PC on the $x$ and $y$ axes. The $x$ axis shows PC1 which accounts for $24 \%$ of the variation in the dataset. PC2 is o the $y$-axis and accounts for $16.5 \%$ of the variation in the dataset. (C) Supervised PLS-DA finds clear separation between the metabolomes of male and female mice. PLS-DA is also shown as a scatterplot of the top two components, with component 1 accounting for $19.7 \%$ and component 2 accounting for $17.7 \%$ of variation within the dataset. The colors in A-C correspond to sample cohorts: blue - control males, orange - control females. (D) Volcano plot analysis displays differentially regulated metabolite features that were distinguished between cohorts using both fold change and false discovery rate (FDR) adjusted $p$-value. When comparing males and females, 126 metabolite features in the upper right quadrant had a fold change $>3$ and a p-value $<0.05$ and these features were significantly higher in control female mice. Similarly, 225 features in the upper left quadrant were associated with control male mice. (E) T-test analysis identified 318 significant metabolites ( $p$-value $<0.05$ ). (F) Fold change analysis was utilized to further examine the differences in metabolomes of female and male mice. 211 metabolite features ( $p$-value $<0.05$ ) with a positive FC correspond to female mice, and 267 metabolite features with a negative FC correspond to male mice. 


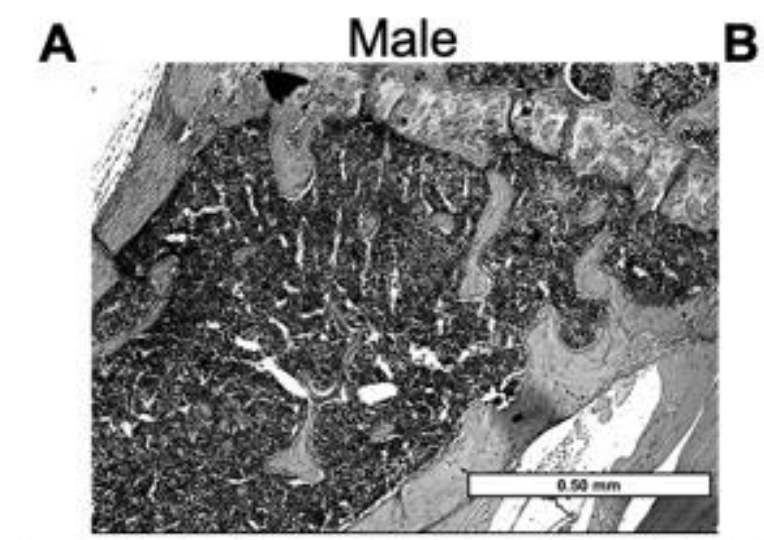

B

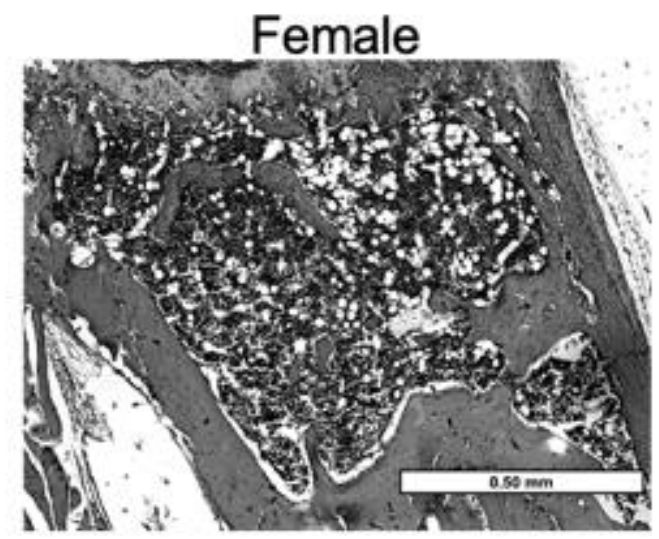

\section{C}

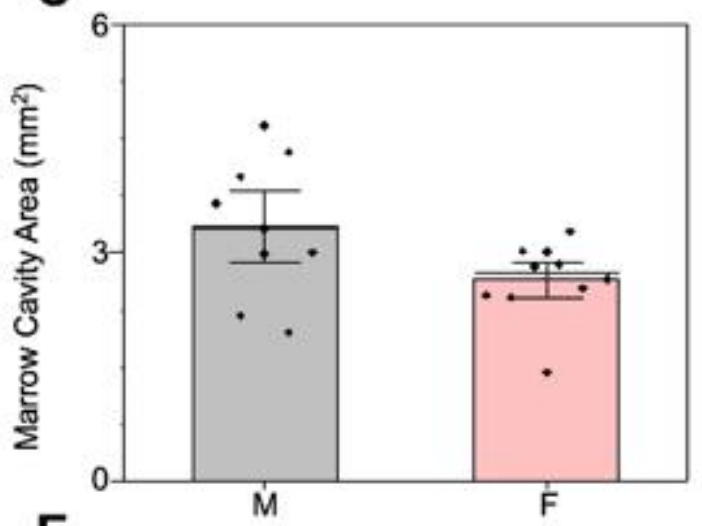

D
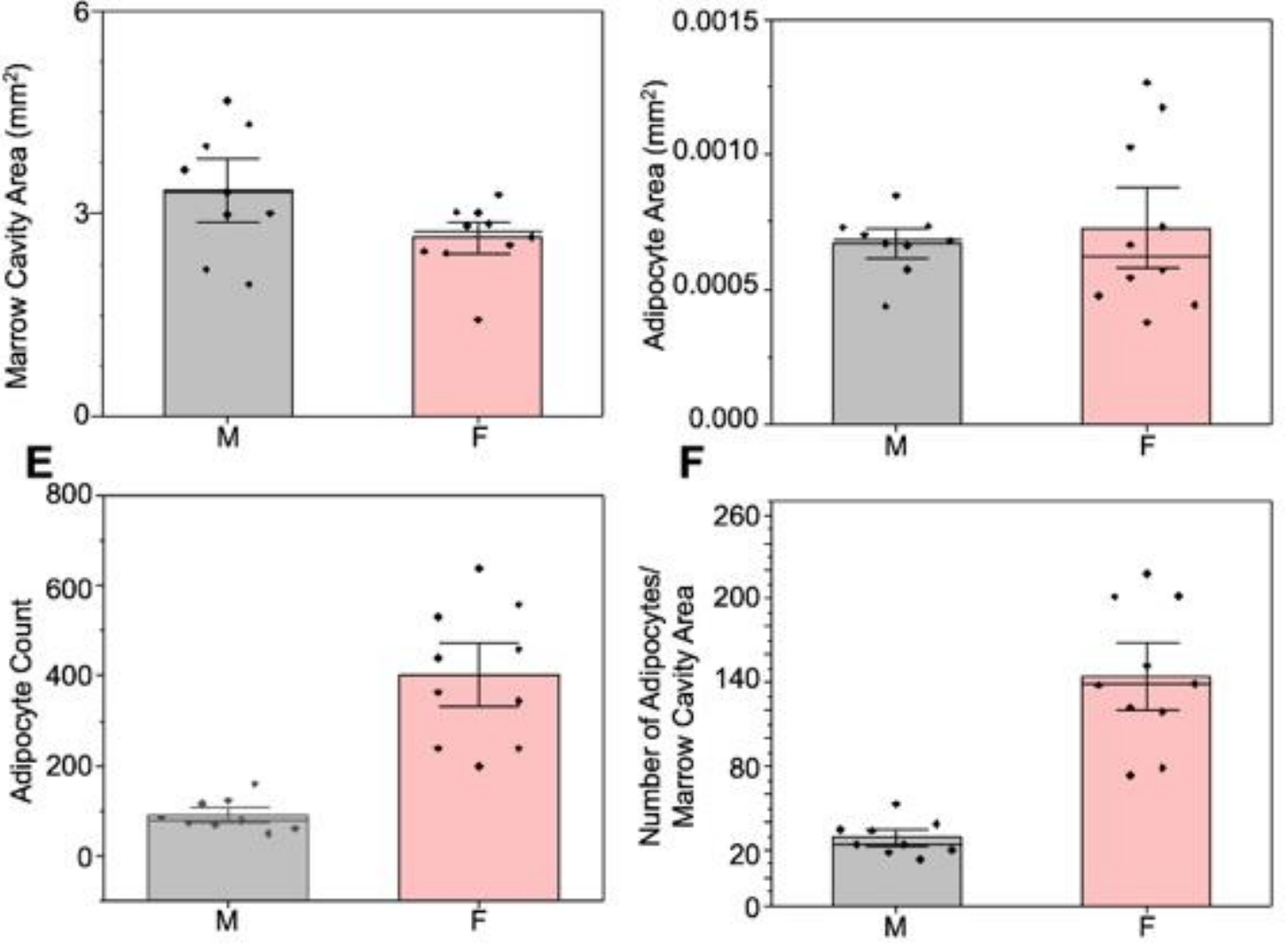

Figure 4. Bone marrow adiposity exhibits sexual dimorphic behavior. (A-B) Male

855 (right) and female (left) H\&E-stained proximal tibia imaged at 4x. Measurements calculated include (C) marrow cavity area, (D) adipocyte area, (E) adipocyte count, and $(F)$ number of adipocytes per marrow cavity area in male and female mice. 


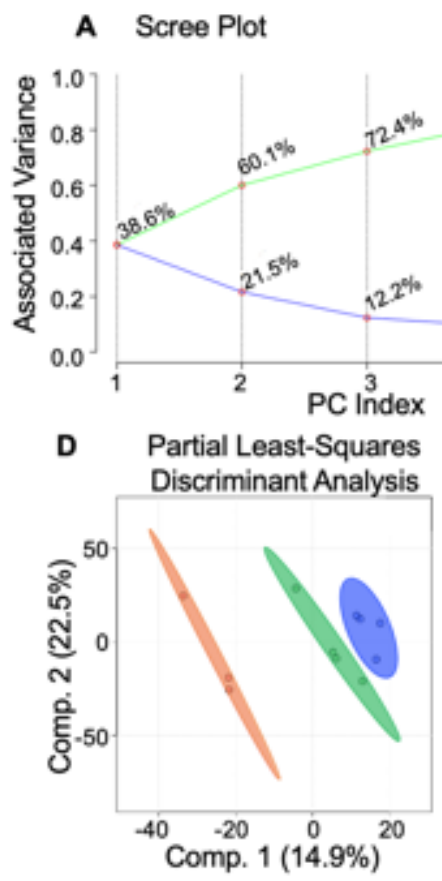

B Principal Components $1 \& 2$

C Principal Components 283

Figure 5. Differences in whole bone mechanical properties, like strength, correspond to metabolic differences in male and female mice. An untargeted metabolomic approach was utilized to generate metabolomic profiles based on whole bone strength. (A) Scree plot reveals how much variation is being captured in each principal component from the data. (B) PCA analysis, captured by PC1 and PC2 show moderate overlap of groups. Together, PC1 and PC2 account for approximately $60 \%$ of the variation in the dataset. (C) Additionally, PCA analysis captured by PC2 and PC3 show improved separation compared to B. (D) PLS-DA analysis displays complete separation of groups. Similarly, component 1 and 2 combined account for $30 \%$ of the variation in the dataset. (E) HCA, visualized by a dendrogram, displays that the metabolome of bone differing by strength somewhat differs. (F) Median intensity heatmap analysis shows that the metabolome of stronger and weaker bones differs from each other, and when accounting for sex. Median intensities were clustered into 3 respective groups via MATLAB to visualize and identify metabolic pathways and 875 features that differ between groups. 